\title{
Austrian syndrome
}

\author{
J B Poulsen, ${ }^{1}$ C Moser, ${ }^{2} \mathrm{~K}$ Espersen, ${ }^{1} \mathrm{~K} \mathrm{Moller}^{3}$ \\ ${ }^{1}$ Department of Intensive Care, Rigshospitalet, University of Copenhagen, Copenhagen OE, Denmark; \\ 2Department of Clinical Microbiology, Rigshospitalet, University of Copenhagen, Copenhagen OE, Denmark; \\ ${ }^{3}$ Centre of Inflammation and Metabolism, Rigshospitalet, University of Copenhagen, Copenhagen OE, Denmark
}

Correspondence to J B Poulsen, jpoulsen@dadlnet.dk

\section{Summary}

The authors present a case of Austrian syndrome, the triad of pneumococcal pneumonia, endocarditis and meningitis, in a 49-year-old woman, who developed severe acute heart failure due to aortic valve destruction. The patient required imminent valve surgery, but eventually recovered.

\section{BACKGROUND}

Austrian syndrome is a triad of pneumococcal pneumonia, meningitis and endocarditis. The clinical presentation of these coexisting infections was first described by an Austrian pathologist, Richard Heschl, in 1862. The affinity of Streptococcus pneumoniae to the aortic valve and the simultaneous presence of meningitis were described in 1957 by the American physician Robert Austrian, hence the eponym. Since the discovery of penicillin, the incidence of infective endocarditis caused by $S$ pneumoniae has decreased dramatically. However, although pneumococci are now regarded as uncommon agents of infectious endocarditis accounting for $<3 \%$ of cases ${ }^{1}$ endocarditis due to this bacterium often runs a fulminant course with rapid valvular destruction, which necessitates early and aggressive surgical intervention. Austrian syndrome is a clinical rarity with an incidence of $1.2 \%$ among those with infectious endocarditis ${ }^{2}$ and a very high mortality. Early diagnosis is essential for optimal treatment and a good prognosis. We present a case of Austrian syndrome complicated with aortic valvular destruction, acute cardiac failure and emergency valve replacement.

\section{CASE PRESENTATION}

A 49-year-old woman presented to the medical emergency department with fever and an impaired level of consciousness. The patient had a history of chronic alcohol abuse, but was otherwise reportedly healthy. She had a 7-day history of fever of up to $40.7^{\circ} \mathrm{C}$, malaise, a cough and diarrhoea. On the day of admission, progressive worsening of weakness, dizziness and disorientation developed. Intravenous benzylpenicillin $5 \mathrm{mIU}$ was administered to the patient, and she was admitted to the hospital. In the emergency room, physical examination revealed disorientation, confusion and agitation with a Glasgow Coma Score of 9. Pupils were dilated and showed no response to light. Petechiae and nuchal rigidity were noted. Vital signs on admission were: heart rate 145 beats/min, respiratory rate 25 breaths/ $\mathrm{min}$ and blood pressure 200/100 mm Hg. On auscultation of the heart, no murmur was detectable. Lung auscultation revealed bilateral coarse rales. No abnormalities were detected on examination of the patient's ears, oral cavity or throat.

\section{INVESTIGATIONS}

Blood tests showed a total white blood cell count of $35 \times$ $10^{9} / 1$ and a level of $C$ reactive protein of $193 \mathrm{mg} / \mathrm{l}$. The remaining results were within normal limits. Chest x-ray revealed minor diffuse infiltrates bilaterally (figure 1).

A CT scan of the cerebrum was unremarkable. A lumbar puncture showed purulent cerebrospinal fluid (CSF) with the following results: CSF white blood cell $11500 \times 10^{6} / 1$ and CSF glucose $0.2 \mathrm{mmol} / \mathrm{l}$ (blood glucose $10.1 \mathrm{mmol} / \mathrm{l}$ ). No bacteria were detected by direct microscopy, and the cultures from CSF were negative. However, pneumococcal antigen was detected in the CSF, and a positive PCR test later confirmed the presence of bacterial DNA from $S$ pneumoniae in the CSF. Cultures from sputum and a pneumococcal urine antigen test were negative.

\section{TREATMENT}

The patient was intubated and admitted to the intensive care unit. Bacterial meningitis secondary to pneumonia was suspected. Intravenous ceftriaxone, ampicillin and dexamethasone were administered following normal guidelines for treatment of bacterial meningitis of unknown aetiology. The condition rapidly progressed to septic shock, requiring intravenous fluid resuscitation and vasopressor treatment. Therapy according to the guidelines of the 'surviving sepsis campaign' was initiated. ${ }^{3}$ The patient responded well to the therapy; over the next days her overall status improved. On the 5th day of admission, however, a new chest x-ray showed enlarged cardiac silhouette consistent with cardiomegaly (figure 2). A slight increase in heart rate and diastolic hypotension was also reported in the medical chart.

The condition rapidly deteriorated and over a few hours the patient became progressively haemodynamically unstable with a tachycardia of 140 beats $/ \mathrm{min}$ and severe diastolic hypotension with a blood pressure of $114 / 22$ (mean arterial pressure, $40 \mathrm{~mm} \mathrm{Hg}$ ). 


\section{BMJ Case Reports}

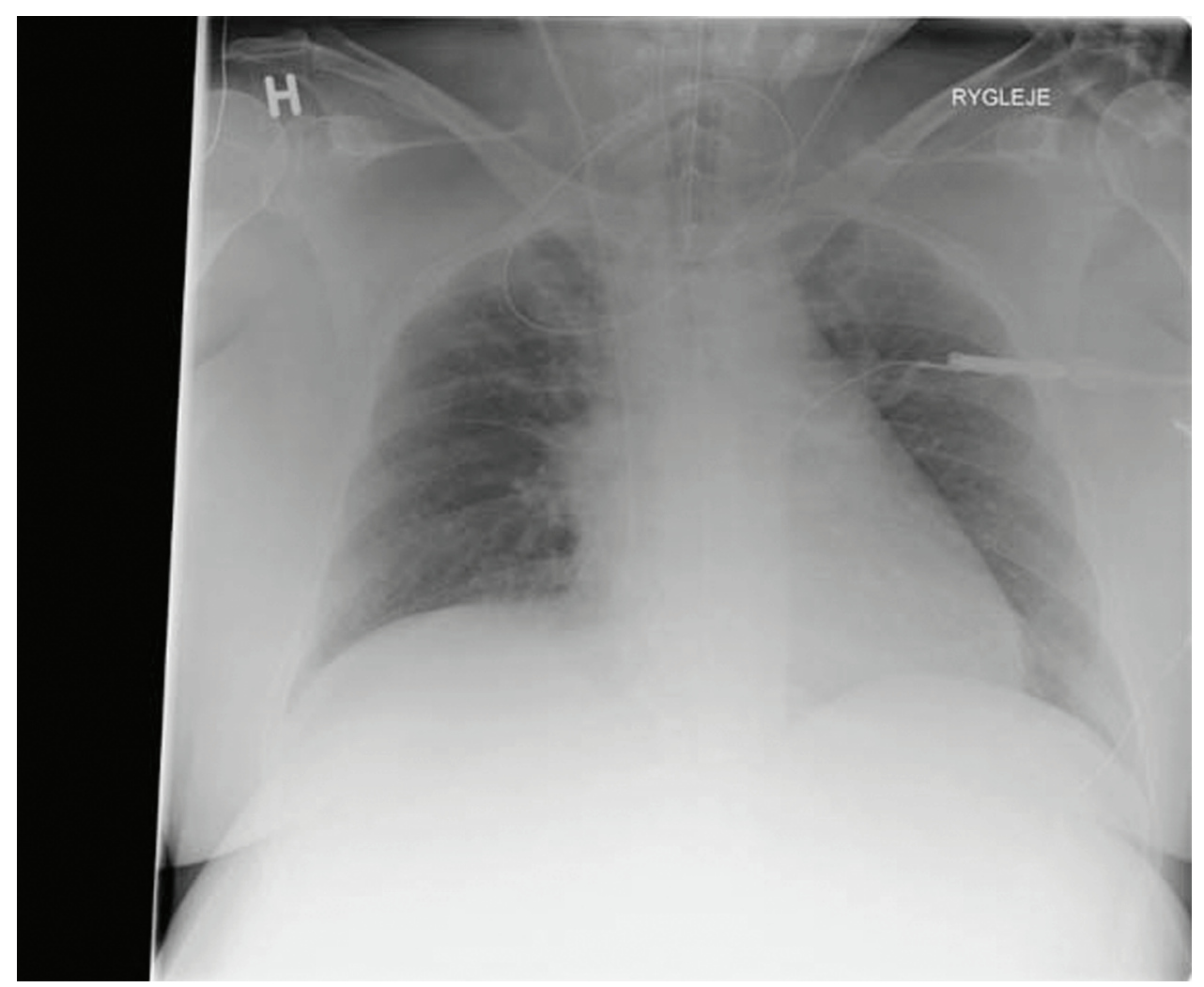

Figure 1 Chest x-ray on admission.

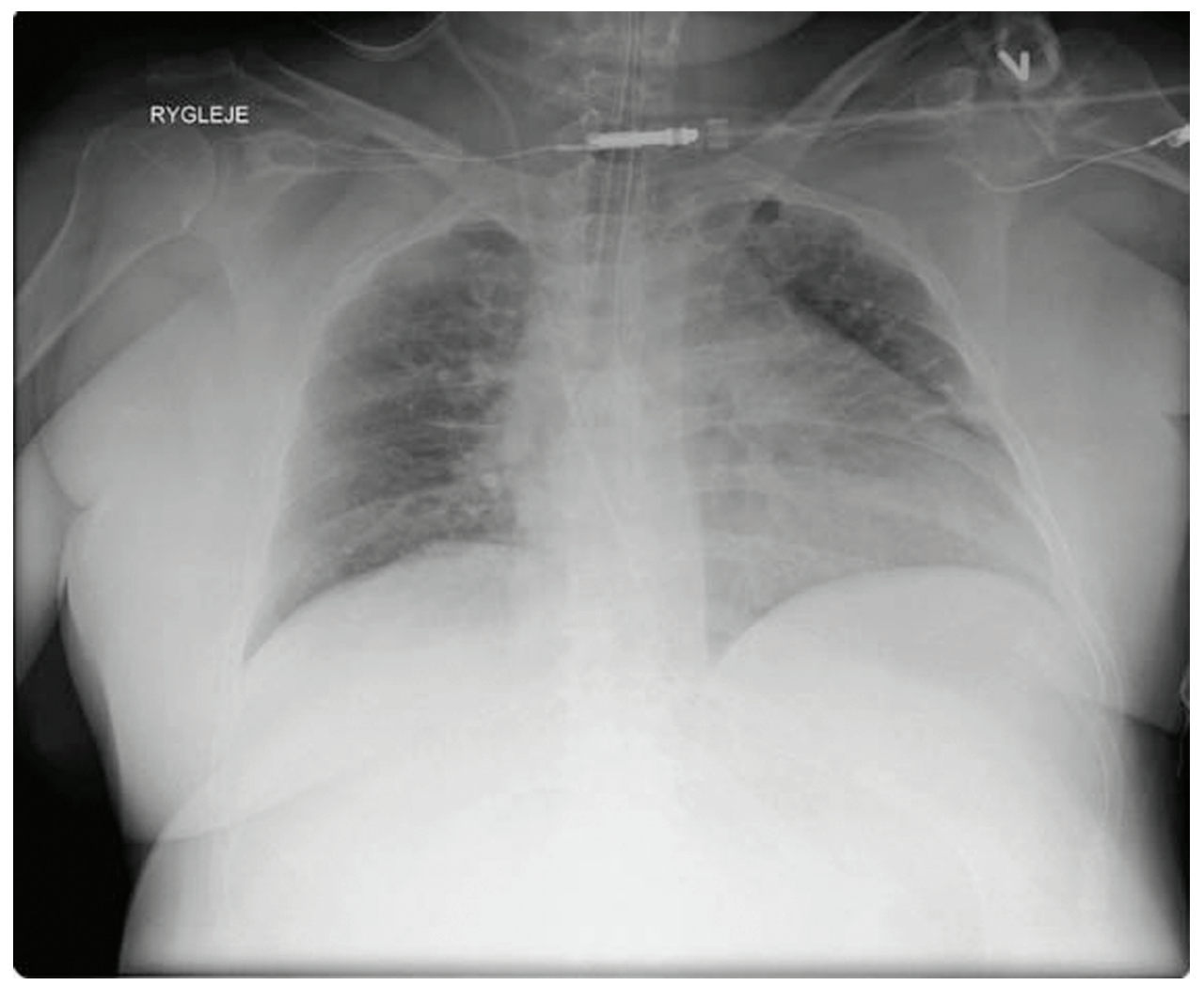

Figure 2 Chest x-ray on day 5. An enlarged cardiac silhouette is present.

Auscultation of the lungs revealed bibasal rales. Left ventricular dysfunction was suspected based on the chest $\mathrm{x}$-ray. Because of additional severe respiratory compromise, the inspired oxygen fraction was increased to $70 \%$ and the positive end expiratory pressure was increased to 20 $\mathrm{cm} \mathrm{H}_{2} \mathrm{O}$. An ECG revealed a sinus tachycardia with no 
signs of hypertrophy or ischaemia. Immediately following an inconclusive acute transthoracic echocardiography (TTE) performed bed-side by a trained cardiologist, a transoesophageal echocardiogram (TEE) revealed a total prolapse of the left coronary cusp of the aortic valve, with a massive regurgitating jet leading to severe aortic insufficiency. The patient was transferred for emergency heart surgery, during which severe destruction of the left coronary cusp and marked pendling vegetations on the noncoronary cusp were found. Due to age considerations and the unconscious state of the patient, the aortic valve was replaced by a mechanical prosthesis (Avantage nr. 21) (figure 3) adhering to international recommendations. ${ }^{4}$ Microscopy of the native valve revealed Gram-positive diplococci in microcolonies, with capsules surrounding some of the diplococci. Culture, however, remained without bacterial growth.

\section{OUTCOME AND FOLLOW-UP}

The patient was discharged 2 months after admission without any sequelae. On follow-up at 6 months, the course of the recovery was uneventful, and still no sequelae were present.

\section{DISCUSSION}

In the setting of bacterial endocarditis, the development of acute aortic insufficiency is generally considered to represent a haemodynamically unstable situation with high mortality. Even with appropriate antibiotic administration, the reported mortality of patients receiving non-surgical treatment is up to $60 \%$, compared to a combined aggressive medical-surgical approach which carries a mortality of $32 \% .^{5}$ Thus, an early diagnosis and, in the case of aortic valve destruction, immediate valve replacement, appear to be essential for survival.

The definite diagnosis of endocarditis caused by $S$ pneumoniae is often delayed for a number of reasons, such as the absence of the classical stigmata of endocarditis and a late occurrence of pathological cardiac murmurs. ${ }^{6}$ For this purpose, TEE is superior to TTE in diagnosing valvular vegetations, abscesses and perforations; according to one report, these serious complications went undetected in at least $42 \%$ of the cases when using TTE. ${ }^{7}$ When clinical signs of endocarditis eventually appear, the presentation is often fulminant, and haemodynamic instability immediately precedes circulatory collapse. Also, the coexistence of other foci of infection that justify the patient's general symptoms is a confounding factor in the delay of diagnosis. In agreement with these considerations, our patient did not show any significant or specific cardiovascular abnormalities that could not be explained by the presence of severe sepsis, prior to the rapid development of manifest haemodynamic collapse. Acute deterioration over a short period of time was seen, and before endocarditis was recognised clinically, the patient progressed into congestive heart failure secondary to destruction of the aortic valve. Retrospectively, the history of chronic alcohol abuse and pneumococci in the CSF should have prompted a focused search for endocarditis; however, the fact that all cultures were negative probably contributed to the diagnostic delay. The most likely reason for this is the administration of antibiotics prior to obtaining blood culture and CSF.

According to commonly accepted guidelines, ${ }^{4}$ surgery should be considered as soon as the definite diagnosis of bacterial endocarditis has been established even if

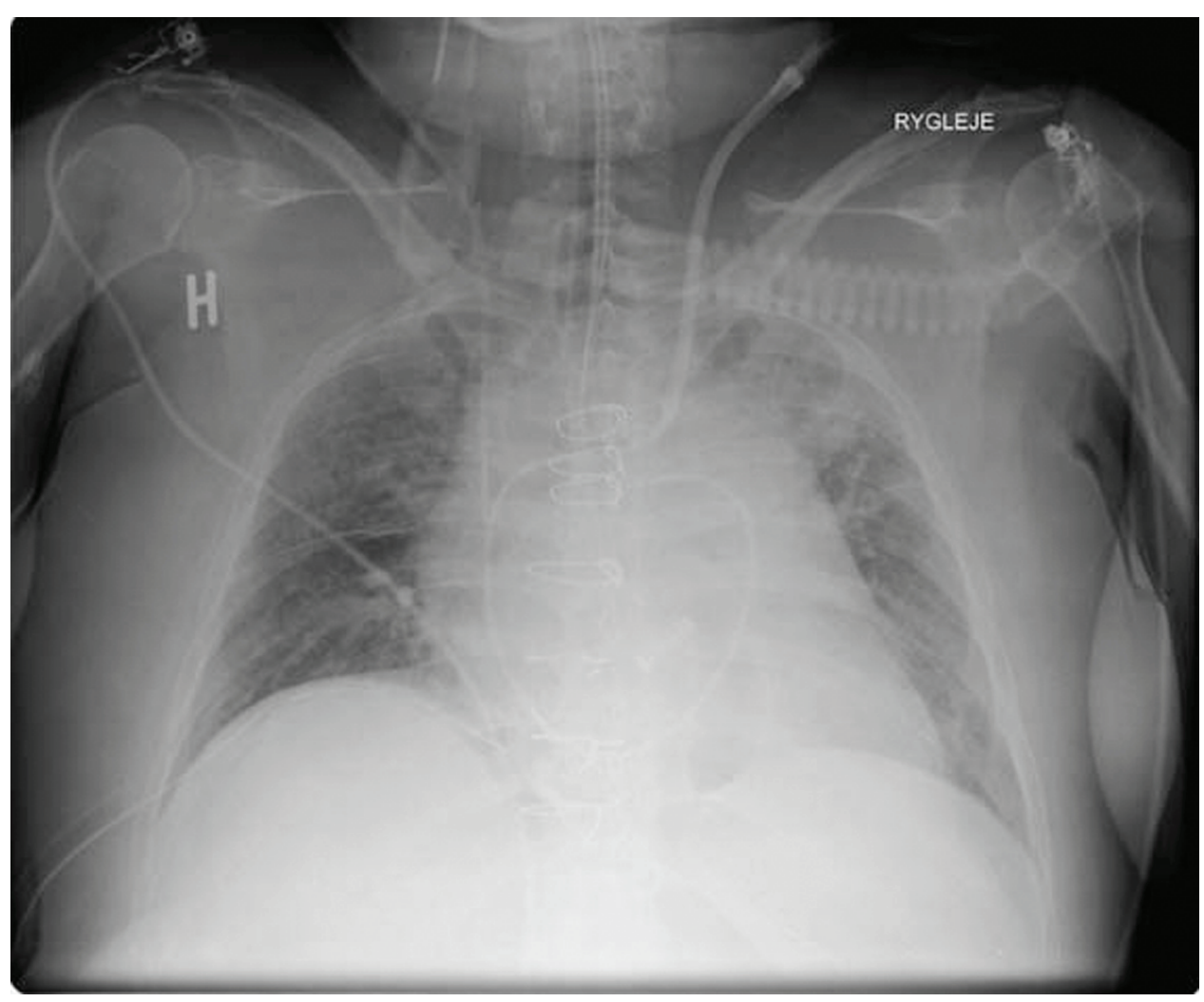

Figure 3 Chest x-ray after surgery. 


\section{BMJ Case Reports}

\section{Learning points}

- Austrian syndrome is a rare occurrence, but when meningitis and pneumonia are present together, especially if caused by $S$ pneumonia and in alcoholic patients, the coexistence of a concomitant bacterial endocarditis should be considered.

- In congruence with previous reports, the present case supports that TEE is superior to TTE in diagnosing valvular pathology.

- In the presence of bacterial endocarditis, antibiotic therapy may not prevent the development of acute and severe cardiac failure. When a definite diagnosis is achieved, early surgical evaluation is necessary.

- In the haemodynamically unstable patient with pneumococcal meningitis, a transoesophageal echocardiography should be considered in order to verify or rule out the presence of endocarditis.

congestive heart failure has not yet developed and despite the known risks of valve replacement; this approach may obviate the need for an emergency procedure, which carries a high mortality. In the presence of meningitis, such as in our patient, intraoperative intracranial pressure monitoring may be helpful to guide ventilatory settings and haemodynamic management.

Competing interests None.

Patient consent Obtained.

\section{REFERENCES}

1. Bruyn GA, Thompson J, Van der Meer JW. Pneumococcal endocarditis in adult patients. A report of five cases and review of the literature. $0 \mathrm{~J} \mathrm{Med}$ 1990;74:33-40.

2. Gonzalez-Juanatey C, Testa A, Mayo J, et al. Austrian syndrome: report of two new cases and literature review. Int J Cardiol 2006;108:273-5.

2. Levy MM, Fink MP, Marshall JC, et al. 2001 SCCM/ESICM/ACCP/ATS/SIS International Sepsis Definitions Conference. Crit Care Med 2003;31:1250-6.

4. Bonow RO, Carabello BA, Kanu C, et al. ACC/AHA 2006 guidelines for the management of patients with valvular heart disease: a report of the American College of Cardiology/American Heart Association Task Force on Practice Guidelines (writing committee to revise the 1998 Guidelines for the Management of Patients With Valvular Heart Disease): developed in collaboration with the Society of Cardiovascular Anesthesiologists: endorsed by the Society for Cardiovascular Angiography and Interventions and the Society of Thoracic Surgeons. Circulation 2006;114:e84-231.

5. Aronin SI, Mukherjee SK, West JC, et al. Review of pneumococcal endocarditis in adults in the penicillin era. Clin Infect Dis 1998;26:165-71.

6. Collazos J, Garcia-Cuevas M, Martinez E, et al. Prosthetic valve endocarditis due to Streptococcus pneumoniae. Arch Intern Med 1996;156:2141, 2146, 2148

7. Daniel WG, Mügge A. Transesophageal echocardiography. N Engl J Med 1995; 332:1268-79.

This pdf has been created automatically from the final edited text and images.

Copyright 2011 BMJ Publishing Group. All rights reserved. For permission to reuse any of this content visit http://group.bmj.com/group/rights-licensing/permissions.

BMJ Case Report Fellows may re-use this article for personal use and teaching without any further permission.

Please cite this article as follows (you will need to access the article online to obtain the date of publication)

Poulsen JB, Moser C, Espersen K, Moller K. Austrian syndrome. BMJ Case Reports 2011;10.1136/bcr.09.2010.3368, date of publication

Become a Fellow of BMJ Case Reports today and you can:

- Submit as many cases as you like

- Enjoy fast sympathetic peer review and rapid publication of accepted articles

- Access all the published articles

- Re-use any of the published material for personal use and teaching without further permission

For information on Institutional Fellowships contact consortiasales@bmjgroup.com

Visit casereports.bmj.com for more articles like this and to become a Fellow 